\title{
Do patients presenting to accident and emergency departments have low serum anticonvulsant concentrations?
}

D. G. SNOW, S. H. D. JACKSON, D. SKINNER, R. MAINWARING BURTON \& A. H. WILLIAMS

* Accident and Emergency Department, Lecturer in Clinical Pharmacology and Consultant in Accident and Emergency Medicine, St Bartholomew's Hospital, London and Principal Biochemists, Homerton Hospital, Hackney, London

\section{SUMMARY}

It is often felt that poorly controlled epileptic patients, who are taking anticonvulsant medication, are over represented in A\&E departments compared to the general population. This A\&E based study set out to determine whether such patients do have inadequate serum anticonvulsant levels, when they present following a seizure, to A\&E departments. All epileptic patients, taking medication, who presented to the A\&E departments of St. Bartholomew's and Hackney Hospitals, London, over a 4-month period were studied. Serum anticonvulsant concentrations were measured on their arrival in the departments. Forty-six patients were studied. Only $21 \%$ of anticonvulsant drug concentrations were within 'therapeutic' ranges. A total of $66 \%$ were below 'therapeutic' ranges and $13 \%$ were potentially toxic. The implication of these findings is discussed.

\section{INTRODUCTION}

The concentration effect relationship for some anticonvulsants, such as phenytoin, has been documented, Kutt et al., (1964) and Lund (1974). These studies have defined ranges of serum phenytoin concentrations that are associated with reduced fit frequencies on the one hand, and an increased prevalence of adverse reactions on the other. For anticonvulsants, such as sodium valproate, control of seizures

Correspondence: Mr. D. G. Snow FRCS, Registrar, ENT Department, Sell Oak Hospital, Birmingham B29 6JD, U.K. 
bears little relationship to serum concentration, suggesting partitioning between the blood and effect compartments combined with a relatively short half life.

Seizures in epileptic patients may represent an acceptably infrequent occurrence $\bar{a}$ or be due to inadequate control. This latter situation may be related to inadequate $\frac{\widehat{Q}}{\mathscr{Q}}$ dosage of anticonvulsants, sometimes mediated via a pharmacokinetic drug inter $\stackrel{-}{\Rightarrow}$ action, a change in formulation producing a decreased bioavailability, resist $-\stackrel{\mathscr{N}}{+}$ ance to drugs being given or pharmacodynamic factors such as stress or alcohol withdrawal.

Patients presenting to accident and emergency (A\&E) departments with fits constitute about 1 in 200 of all patients presenting. (Pease 1973). It is often felt that patients with poorly controlled epilepsy are over represented among those seen in $\rightarrow$ A\&E departments, compared with the population as a whole, and that inadequate drug dosage is an important cause of seizures in such patients. As a first step $\vec{\sigma}$ towards investigating the hypothesis that inadequate drug dosage is causallyळ related to presentation to A\&E departments with seizures, we have performed $a$. preliminary observational study. This study was designed to measure serum: anticonvulsant concentrations in patients presenting to A\&E departments within $\vec{A}$ the City and Hackney Health District.

\section{METHODS}

All patients who were known to be receiving drug treatment for epilepsy and wo presented with a seizure to either Hackney Hospital (A\&E department now house at Homerton Hospital) or St. Bartholomew's Hospital A\&E departments over 4-month period were entered into the study. A history was taken paying particularô attention to drug and alcohol ingestion, and including details of compliance with therapy. Any symptoms of drug toxicity were noted. Physical examination was performed in all patients and included a search for signs of toxicity, such as ataxia. Patients unable to give a history at the time of presentation were interviewedo subsequently and, wherever possible, a third party was also interviewed to confirm $\widetilde{\mathbb{D}}$ historical statements. In each case $10 \mathrm{ml}$ of venous blood was taken for serum anticonvulsant assay. These assays were performed by the District Chemical Pathology Laboratories using a non-derivatizing GLC method.

\section{RESULTS}

A total of 46 patients were entered into the study, 34 male and 12 female. The N mean age was 38.5 years (range 18-83), mean time between seizure and presentation $N_{\omega}$ was $1.9 \mathrm{~h}$ (range $0-7$ ) and the mean time since last taking anticonvulsant medication was $7 \cdot 0 \mathrm{~h}$ (range 1-24). Most patients had generalized seizures, partiale seizures were recorded in only two patients. There was no clinical evidence of $\stackrel{\mathscr{\Phi}}{\stackrel{\Phi}{\mathscr{D}}}$ anticonvulsant drug toxicity. Results of serum anticonvulsant concentrations were 
Table 1 Number of patients $(\mathrm{N})$ (and percentage for the row) who claimed to be taking each anticonvulsant together with the number with no detectable drug present, subtherapeutic concentrations, therapeutic concentrations and with potentially toxic serum concentrations.

\begin{tabular}{|c|c|c|c|c|c|}
\hline & $\mathrm{N}$ & $\begin{array}{c}\text { No detectable } \\
\text { drug }\end{array}$ & $\begin{array}{c}\text { Detectable but } \\
\text { potentially } \\
\text { subtherapeutic }\end{array}$ & Therapeutic & Toxic \\
\hline Phenobarbitone & 15 & $3(20 \%)$ & $6(40 \%)$ & $4(27 \%)$ & $2(13 \%)$ \\
\hline Phenytoin & 25 & $8(32 \%)$ & $9(36 \%)$ & $4(16 \%)$ & $4(16 \%)$ \\
\hline Carbamazepine & 13 & $3(23 \%)$ & $6(46 \%)$ & $3(23 \%)$ & $1(8 \%)$ \\
\hline $\begin{array}{l}\text { Sodium } \\
\text { valproate }^{*}\end{array}$ & 4 & $-\quad-$ & - & - & \\
\hline Total & 53 & $14(26 \%)$ & $21(40 \%)$ & $11(21 \%)$ & $7(13 \%)$ \\
\hline \multicolumn{3}{|c|}{ Therapeutic ranges used: } & $\begin{array}{l}\text { phenobarbitone } \\
\text { phenytoin } \\
\text { carbamazepine }\end{array}$ & $\begin{array}{l}: 30-80 \text { umol } \\
: 30-60 \text { umol } \\
: 20-50 \text { umol }\end{array}$ & \\
\hline
\end{tabular}

not available in three out of the 46 patients. Twenty-nine $(67 \%)$ patients took one drug only for their epilepsy, $12(26 \%)$ took two drugs and one patient took three drugs. With the exception of a single patient who took primodone only, patients were taking combinations of phenytoin, phenobarbitone, carbamazepine and valproate. Four patients were unable to state precisely what regular medication they took.

Each serum anticonvulsant concentration, excluding those from the four patients unable to state their medication, was classified as below, within and above the predefined 'therapeutic' ranges for each drug (Table 1). Valproate concentrations have been omitted from the table because of the lack of a simple relationship between serum concentrations and effect.

It was found that 12 of the 46 patients admitted to missing one or more doses of their medication in the week preceding presentation. One patient admitted not taking any medication for 2 weeks prior to his seizure. Of this group of non compliant patients, the majority had subtherapeutic levels (seven out of the 10 with available results). From the group who claimed compliance, nine out 24 measured levels were below 'therapeutic' ranges $(38 \%)$.

\section{DISCUSSION}

Only 11 of $53(21 \%)$ serum anticonvulsant concentration measurements were within, admittedly arbitrary, therapeutic ranges for the drugs that patients gave a clear history of taking. This result is lower than that of McGlone \& Pritty (1986) who reported a figure of 20 out of $53(37.7 \%)$ using different therapeutic ranges. The reasons for low serum concentration of anticonvulsants are many and include inadequate prescribed dosage (sometimes caused by interactions with concurrent 
medication), and non-compliance. Low concentrations may also be seen in patients who have previously been well controlled with serum concentrations below the 'therapeutic' range. Unlike phenytoin and phenobarbitone, but similar to sodium ${ }_{3}^{0}$ valproate, carbamazepine has a relatively short elimination half life during chronic dosing making timing of sampling an important determinant of serum concentration. Perhaps as a result of this, it has been difficult to define therapeutic ranges $\stackrel{\vec{\rho}}{?}$ for both these drugs. No patient admitted to taking a non-anticonvulsant drug that was known to significantly alter the metabolism of their anticonvulsants.

Serum levels of anticonvulsants taken soon after a fit would be expected to. represent the effect site concentrations at the time of the seizure to a greater extentw than random samples taken at the time of out patient clinics when patients may have been particularly compliant.

This preliminary study has demonstrated that patients presenting to two $A \& E \vec{\omega}$ departments do have low serum anticonvulsant concentrations. The results are compatible with, but in no way prove, the hypothesis that low (or absent) serum 3 . concentrations of anticonvulsants are the cause of many patients presenting to $\stackrel{\infty}{-}$ $A \& E$ departments. It would thus be appropriate to proceed to a controlled inter- \pm ventional study in patients presenting to $A \& E$ departments, designed to assess theo effect of raising their serum anticonvulsant concentrations on their subsequent $\overrightarrow{-}$ clinical course.

\section{REFERENCES}

Kutt H., Winters W., Kokenge R. \& McDowell F. (1964) Diphenylhydantoin metabolism, blood levễts and toxicity. Archives of Neurology 11, 642-48.

Lund L. (1974) Anticonvulsant effect of diphenylhydantoin relative to plasma levels. Archives of Neurology 31, 289-93.

McGlone R. \& Pritty P. (1986) Measuring anticonvulsant levels in the Accident and Emergency Department. Archives of Emergency Medicine 3, 141-3.

Pease R. (1973) A study of patients in a London Accident and Emergency Department. Practitioner 211, 634-8. 